Revue Revue de l'histoire des religions

de Ihistoire des religions

Théologie politique et sciences sociales : autour d'Erik Peterson (1890-1960)

\title{
Patrick BRIMIOULle, Das Konzil von Konstantinopel 536
}

Stuttgart, Franz Steiner Verlag (« Roma Æterna », 8), 2020

\section{Sylvain Destephen}

\section{OpenEdition}

\section{Journals}

Édition électronique

URL : https://journals.openedition.org/rhr/11343

DOI : $10.4000 /$ rhr. 11343

ISSN : 2105-2573

\section{Éditeur}

Armand Colin

Édition imprimée

Date de publication : 1 septembre 2021

Pagination : 559-562

ISBN : 978-2-200-93377-7

ISSN : 0035-1423

\section{Référence électronique}

Sylvain Destephen, «Patrick Brimıoulte, Das Konzil von Konstantinopel 536 », Revue de l'histoire des religions [En ligne], 3 | 2021, mis en ligne le 01 septembre 2021, consulté le 04 octobre 2021. URL : http://journals.openedition.org/rhr/11343 ; DOI : https://doi.org/10.4000/rhr.11343

Ce document a été généré automatiquement le 4 octobre 2021.

Tous droits réservés 


\title{
Patrick BRIMIOULLE, Das Konzil von Konstantinopel 536
}

Stuttgart, Franz Steiner Verlag («Roma Æterna », 8), 2020

\author{
Sylvain Destephen
}

\section{RÉFÉRENCE}

Patrick BRIMIOULLE, Das Konzil von Konstantinopel 536, Stuttgart, Franz Steiner Verlag (« Roma Æterna », 8), 2020, 323 p., 24,5 cm, 58 €, ISBN 978-3-515-12666-3.

Dans la riche et longue histoire conciliaire de l'Antiquité, l'assemblée épiscopale réunie à Constantinople en mai-juin 536 par le patriarche Ménas est occultée par les deux conciles œcuméniques qui l'entourent chronologiquement, celui de Chalcédoine en 451 et surtout celui de Constantinople II en 553. Si le terme de concile et son caractère œcuménique figurent dans les sources religieuses jusqu'au IX siècle au moins, en réalité il s'agit d'une réunion ecclésiastique qui a été convoquée par un empereur mais ne possédait pas de prétention universelle. Certes, la présence des titulaires ou des délégués des sièges majeurs (Constantinople, Rome, Antioche, Jérusalem, mais non Alexandrie paralysée par des rivalités internes) lui a donné une exceptionnelle représentativité, mais il s'agit avant tout d'une réunion du synode permanent d'une ampleur certes particulière. Cette institution, attestée depuis le début du $v^{\mathrm{e}}$ siècle, est présidée par l'évêque puis le patriarche de Constantinople et formée des évêques de passage ou convoqués dans la capitale. Concile en miniature ou synode exceptionnel, l'assemblée ecclésiastique de 536 a laissé des actes transmis par une compilation de documents réalisée au milieu du $\mathrm{VI}^{\mathrm{e}}$ siècle par des moines d'un couvent de Palestine et appelée, par son éditeur Eduard Schwartz, la Collectio Sabbaitica. Le présent livre, issu d'une thèse dirigée par le professeur Hartmut Leppin de l'université de Francfort, comble une lacune scientifique, car il constitue la première synthèse consacrée à cette réunion épiscopale. Avouons que le titre du livre ne correspond pas tout à fait à son contenu dans la mesure où le propos de l'auteur dépasse de beaucoup l'étude du synode 
de 536. Sur les quelque 300 pages de synthèse, environ 40 pages (p. 132-155 et 170-187) sont consacrées précisément aux actes synodaux que le reste du livre replace dans leur contexte ecclésiologique, dogmatique et historique. Il aurait été utile d'ajouter un soustitre au livre pour orienter et prévenir le lecteur de son contenu.

2 Après le premier chapitre en forme de brève introduction soulignant avec insistance le manque d'études consacrées au synode de 536, le deuxième chapitre propose une récapitulation des événements ecclésiastiques survenus durant le long règne d'Anastase (491-518), en particulier la politique religieuse de cet empereur. Il est question de la rapide déposition du patriarche de la capitale Euphémius, puis de l'hostilité ouverte du souverain à la christologie définie à Chalcédoine qui entraîne la destitution de Macédonius du patriarcat de Constantinople, le remplacement de Flavien par Sévère sur le trône d'Antioche et des troubles en Orient, enfin une émeute confessionnelle dans la capitale et une insurrection armée dans les Balkans (sur ces derniers points on lira avec intérêt les travaux de Jakob Speigl, Frédéric Alpi et Mischa Meier). Relevons un passage intéressant sur le rôle des diptyques sacrés dans la construction d'une identité religieuse collective par l'insertion ou l'exclusion de patriarches et de conciles sur cette liste lue durant la liturgie eucharistique (p. 54-56, cf. p. 247-251). En revanche, on peut se demander si le monachisme syrien se distingue par son fanatisme et sa violence, comme l'auteur l'affirme (p.68). Dans l'Antiquité tardive, des exemples de violence monastique sont également attestés en Égypte, en Palestine, en Mésopotamie et à Constantinople. Les moines sont plus discrets en Asie Mineure et dans les Balkans. Le troisième chapitre évoque la politique religieuse de l'empereur Justin I $\mathrm{I}^{\mathrm{er}}$ (518-527) qui, par le biais d'une réunion du synode permanent en juillet 518, fait proclamer le dogme de Chalcédoine, puis rétablit avec le siège romain la communion rompue depuis trente-cinq ans. Toutefois, l'auteur souligne, avec raison, la persistance de lignes de division doctrinale au sein du camp chalcédonien durant l'affaire dite des moines scythes plus ouverts aux différentes interprétations de la théologie cyrillienne (p. 93-96 et 105).

3 Le quatrième chapitre traite de manière narrative, en une vingtaine de pages, de l'histoire religieuse de la décennie qui sépare l'avènement de Justinien du synode de 536. La période est marquée par les efforts personnels de l'empereur qui, dans ses déclarations théologiques, ses entremises ecclésiastiques et ses ajouts hymniques (p.118-120, cf.p. 254-255, 260), tente en vain de concilier chalcédoniens et monophysites. Seul le cinquième chapitre traite du synode de 536. De manière originale, l'auteur ne considère pas les décisions prises par cette assemblée épiscopale, qualifiée tour à tour de concile et de synode, comme une condamnation du monophysisme, mais "plutôt comme un conflit au sein du camp chalcédonien " (p. 127, cf. p. 152). Celui-ci serait divisé entre un courant favorable à un compromis avec les monophysites et représenté par Justinien et l'ancien patriarche Anthime de Constantinople, ce dernier étonnamment disculpé de tendance monophysite (p. 165 et 191), et un autre courant intransigeant incarné par le patriarche Ménas, le pape Agapet et surtout des moines syro-palestiniens et constantinopolitains (voir sur ces derniers les réflexions intéressantes p. 212-217). En raison du caractère autoritaire du règne de Justinien, il est toutefois difficile de penser que le synode permanent, réuni dans la capitale à son instigation et non de manière indépendante, puisse adopter des décisions contraires à ses attentes, voire critiquer et condamner sa politique religieuse (p. 200 sqq.). L'auteur soupçonne à plusieurs reprises la présence dans les actes 
synodaux de critiques cachées et de condamnations voilées de Justinien, mais ces interprétations sont assez hypothétiques. Il paraît excessif de considérer que «l'empereur n'avait d'autre choix que de suivre le jugement du pape» (p.166), et, qu'en 536, « les évêques soumettaient de manière implicite l'empereur, au moins dans les affaires ecclésiastiques, à l'autorité du pape ou du clergé » (p. 208, cf. p. 226). En réalité, la condamnation par le synode en 536 des principaux chefs monophysites est soutenue et voulue, acceptée et confirmée par l'empereur, comme l'atteste sa novelle 42 promulguée deux mois après la fin du synode et qui en valide les décisions. Par ailleurs, au cours des années 530-550, la question théopaschite et surtout l'affaire des Trois Chapitres prouvent que l'autorité impériale, sacralisée à l'extrême par la conception théocratique du pouvoir de Justinien, s'impose à tous, même au patriarche de Constantinople et à l'évêque de Rome.

4 Séance après séance, acte après acte, lettre après lettre, tout le déroulement du synode est évoqué en détail. Dans le présent livre, l'analyse se concentre de préférence sur l'aspect événementiel et le contenu doctrinal et argumentatif des pétitions et des discussions enregistrées dans les procès-verbaux du synode. Le choix et l'emploi des citations scripturaires et patristiques sont peu commentés. De même, les aspects plus documentaires comme le caractère procédural du synode, l'enregistrement des débats, la présence ou l'absence du grec, du latin et du syriaque, la transcription des actes et, de manière plus large, la composition de la Collectio Sabbaitica, ont moins retenu l'attention. Ajoutons que la prosopographie religieuse - hormis les cas ici bien étudiés du patriarche Anthime et du moine Zooras condamnés en 536 (p. 155-166 et 181-184) -, l'administration ecclésiastique, la géographie monastique et la toponymie religieuse ne suscitent aucun commentaire. Par ailleurs, certains sièges épiscopaux ont reçu une graphie assez inattendue (e.g. Pissinuntos, Ptolomais, Synadeos). Le sixième et avantdernier chapitre est le plus original du livre, même s'il est éloigné des actes du synode de 536. Il propose d'étudier la formation des identités collectives religieuses en fonction de la position doctrinale et de l'influence personnelle, à la fois spirituelle et morale, de certaines figures issues, pour l'essentiel, de l'épiscopat. Les identités religieuses s'organisent au sein du christianisme nicéen en communautés ecclésiales opposées qui dépendent d'abord de la capacité personnelle de certaines figures d'autorité. Ces dernières constituent un réseau de fidèles par l'affirmation et la transmission de particularités théologiques et liturgiques qui, tout en cherchant à justifier et agréger les fidèles et condamner et exclure les hérétiques au nom de l'orthodoxie et de l'orthopraxie - celle-ci l'emportant parfois sur celle-là -, se révèlent en réalité perméables et évolutives. Ces identités doctrinales labiles peuvent en outre se combiner à des motivations individuelles ou à des revendications non religieuses de nature plus politique ou matérielle. L'auteur montre, de manière convaincante, qu'il faut renoncer à une présentation dichotomique de l'opposition entre chalcédoniens et monophysites (p. 243, cf. p. 268).

5 En guise de conclusion, un septième chapitre, d'une demi-douzaine de pages seulement, offre un petit aperçu de la réaction de Justinien au synode de 536. L'auteur évoque les nouveaux efforts de l'empereur pour un rapprochement avec les monophysites. Il considère qu'en 536 Justinien s'est retrouvé en position de faiblesse vis-à-vis des "attaques des ecclésiastiques" et même victime des "critiques de sa politique religieuse » (p. 306, 307). Cela expliquerait son choix de réunir un concile œcuménique en 553. Considérer Justinien comme un empereur faible face aux clercs et aux moines surprend quand on lit sa législation disciplinaire et doctrinale qui a mis en ordre et au 
pas les milieux ecclésiastiques et monastiques avec une autorité sans précédent. Le livre est complété par une bibliographie assez resserrée, qui privilégie la littérature scientifique de langue allemande et anglaise, et qui n'est pas exempte d'oublis ni de coquilles. De plus, certaines références indiquées dans les notes de bas de page sont absentes de la bibliographie. C'est, par exemple, le cas de l'étude de Sebastian Scholz, Transmigration und Translation. Studien zum Bistumswechsel der Bischöfe von der Spätantike bis zum Hohen Mittelalter, parue à Cologne en 1992 et dont l'auteur fait un large usage p.166-169. L'absence d'un index général des citations bibliques, patristiques et littéraires, des noms de personnes et des noms de lieux est également regrettable. Malgré ces petits oublis, le livre constitue désormais une étude marquante sur le contenu doctrinal du synode réuni à Constantinople en 536.

\section{AUTEURS}

\section{SYLVAIN DESTEPHEN}

Université Paris Nanterre. 